\title{
Papers
}

\section{Data protection: Where are we now?}

Received (in revised form): 1st November, 2008

\begin{abstract}
James Castro Edwards
is a graduate from Queen Mary College, London University, and is a solicitor at Speechly Bircham LLP in the intellectual property technology and commerce team. James specialises in data protection, e-commerce and computer games. James' data protection work includes advising and project-managing global data protection compliance programmes for multi-national companies and advising on cross-border data protection issues, providing data protection advice to companies in complex commercial transactions involving the processing of personal data, assisting companies in optimising their databases for marketing purposes and providing data protection advice in the context of corporate acquisitions or disposals.
\end{abstract}

\section{Keywords personal information, data protection law, compliance}

Abstract This paper considers the extent to which data protection legislation in the UK and EU has achieved its original aims, explains some proposed changes to the UK Data Protection Act 1998 and developments in EU legislation, and takes a brief look at the data protection legislative regimes in the APEC countries and the US.

Journal of Database Marketing \& Customer Strategy Management (2008) 15, 285-292.

doi:10.1057/dbm.2008.18

\section{INTRODUCTION}

Data protection is an issue that is increasingly hitting the headlines. In the UK, high-profile data losses appear in the news with such frequency that public awareness of the importance of protecting personal information has never been greater. This coincides with, and is accentuated by, an emerging 'information society' where individuals, in their personal and working lives, exchange vast amounts of personal data via the internet, on a daily basis. In this sense, data protection has come of age. Now it is no longer viewed as a bureaucratic obstacle, but an important protection of individuals' rights. In the European Union $(\mathrm{EU})$, the most mature data protection regime, data protection legislation has been in place for some time throughout its member states, and European data protection law has been 'tried and tested'. The legislation that aimed to protect individuals' rights was, however, drafted in a very different time: internet use, and the use of electronic communications by individuals and businesses alike, were far less widespread. Indeed, the concepts of usergenerated content, social networking and Web 2.0 were nonexistent. Now is a timely point to consider whether data protection laws have kept up with developments, and to ask where we are now with data protection.

Notwithstanding some shortcomings, EU data protection law has served to lead the way for the rest of the world, with other jurisdictions following suit by introducing legislation aimed to protect individuals' personal data. This paper first looks at the UK, and considers the extent to which the Data Protection Act (DPA) achieves its original aims, turning to its recognised weaknesses and proposed developments. It then considers developments in data 
protection throughout the EU, as the data protection directive from which the DPA originated comes of age. As already mentioned, data protection is not just a UK- or EU-centric issue: globally, jurisdictions are recognising the importance of creating an environment that protects individuals' personal information. This paper takes a brief look at the global picture, as around the world jurisdictions develop legislation to address the issue. Having looked at some highlights from a global perspective, this paper then examines some experiences of players in the global economy, looking at those multinational and global organisations that find themselves processing data in a large number of different jurisdictions; each of which may have a different approach to data protection. This paper also considers the extent to which global and multinational organisations can take a 'one-size-fits-all' approach to data protection compliance.

\section{THE UK}

It could be said by anyone in favour of a more powerful UK data protection regulator that money simply could not buy the advertising that the UK Government has provided their cause, free of charge. The last two years have seen so many highprofile data protection breaches that data protection is at last taken seriously by members of the public, who, not so long ago, may not have given the issue a second thought. There are too many data protection disasters to list in this paper. To give some examples, however, most recently, on 13th October, the Ministry of Defence lost a disk containing the personal details of up to 1.7 million people who had enquired about joining the armed forces. In some cases, the information included personal information such as next-of-kin details, passport and National Insurance numbers, drivers' licence and bank details, and National Health Service numbers. In September, a computer hard drive containing the details of around 5,000 employees of the justice system, including prison staff, was lost by the Ministry of Justice. Perhaps the government's piece de resistance was the loss, last November, of the entire child benefit database, containing the personal details of 25 million people, including their bank details, National Insurance numbers and information about their children. With such high-profile data security breaches, public awareness of data protection issues has never been greater. To illustrate public consciousness of the issue, a survey conducted by the Information Commissioner's Office (ICO) in March of this year revealed that eight out of ten people are taking greater care to protect personal information following recent data loss blunders, and seven out of ten individuals feel powerless about how their personal information is looked after. ${ }^{1}$

Where once the public may have dismissed the DPA 1998 as unnecessary red tape, with so many high-profile breaches its value as a means of protecting important rights has recently become readily apparent. As public awareness of data protection increases, it is time to ask whether the DPA actually achieves what it set out to do.

\section{DOES THE DPA DO WHAT IT SAYS ON THE BOX?}

The DPA came into force on 1st March, 2000, implementing the Data Protection Directive 95/46/EC (Directive) as law in the UK. The Directive's aim was to harmonise the data protection requirements of the EU countries, in order to facilitate the development of commerce, particularly electronic commerce. Under the Directive, individuals have the following rights from subsequent data users: to know where their data originated, to access their personal data, to rectify inaccurate data and to refuse permission for personal data to be used in certain circumstances. The Directive also established rules to ensure that personal data are only transferred to those countries 
outside the European Economic Area (EEA) that can guarantee equivalent levels of protection, to avoid data controllers simply circumventing their obligations by transferring personal data outside the ambit of the Directive.

The DPA is enforced by the ICO, which has legal powers to ensure that organisations comply with their DPA obligations. The ICO has legal powers including the power to issue information and enforcement notices, conduct audits and prosecute offenders. This is, however, a key area where the DPA comes under criticism. Although receiving such a notice may be damaging to an organisation's reputation, the fines that the ICO can currently issue are minimal and are a limited deterrent. Accordingly, the DPA is to some extent regarded as toothless legislation. The ICO recognises this and has been calling for greater powers for some time.

There are a number of other criticisms of the DPA, perhaps aired more among practitioners than the general public. One issue is the definition of sensitive personal data. Sensitive personal data is a special category of data defined by the DPA, which requires a higher standard of care by data controllers. Sensitive personal data is defined as data that relates to an individual's racial or ethnic origin, political opinions, religious or similar beliefs, membership of a trade union, physical or mental health, sex life or details relating to criminal offences. The rationale behind legislators creating this subset of personal data is that it represents a type of data that could potentially cause the data subject more damage than nonsensitive information such as an e-mail address or telephone number. The DPA definition of sensitive personal data does not, however, include financial information. In an age where 'cybercrime' is rife, financial information is a form of personal data that could potentially cause an individual considerable damage, and there is a persuasive argument that this should be included in the definition of sensitive personal data.

Another issue where the DPA attracts criticism relates to the definitions of data controller and data processor. The rationale for the inclusion of the definitions in the Directive was to establish who should be made legally responsible for processing data securely. The roots of the existing definitions stretch back to the technology sector of the 1980s, which has of course evolved enormously in the intervening two decades. Data protection practitioners are increasingly finding the distinction between controllers and processors blurred, making it unclear who should be responsible for compliance with the DPA, and it has been suggested that this area of the DPA is ready for an overhaul.

A further criticism of the DPA is that the Directive aimed to harmonise the approach taken by EU member states to data protection. As will be explained further in this paper however, there are in fact significant discrepancies between the local implementing data protection laws and the approaches taken by local regulators. This is not just a criticism of the DPA, but can also be levelled at the other EU laws that implement the Directive in the various member states.

\section{PROPOSED DEVELOPMENTS IN THE DATA PROTECTION ACT}

There have been two significant developments in the DPA during 2008. The first development is the Criminal Justice and Immigration Act (CJIA), which received royal assent on the 8th May, 2008. A further development is the Consultation on the Information Commissioner's inspection powers and funding arrangements under the DPA 1998 (Consultation), which was launched on 16th July, 2008. ${ }^{2}$ Both developments potentially strengthened the DPA, first by increasing the potential fines and penalties for serious breaches and 
secondly by giving the Information Commissioner a statutory power to gain entry to premises to audit their dataprocessing facilities.

The CJIA gives the Secretary of State the power to introduce unlimited fines or up to two years' imprisonment for offences under Section 55 of the DPA. Under this section, it is an offence to obtain, disclose or procure the disclosure of confidential or personal information without the consent of the organisation that holds that information. The ICO said of the new power that it 'will act as a strong deterrent and help to ensure that organisations take their data protection obligations more seriously'.

The ICO's right of inspection was addressed by the Consultation, which seeks views on the implementation of two specific recommendations. The first recommendation is that the ICO should have a statutory power to gain entry to relevant premises to carry out an inspection, with a corresponding duty of the organisation to cooperate and supply any necessary information. The second recommendation relates to changes to the notification fee, payable by data controllers to the ICO, through the introduction of a tiered system to ensure that the ICO receives a significantly higher level of funding to carry out its enhanced duties. Currently, data controllers, who notify with the ICO, are required to pay a fee of $\mathcal{E} 35$. The proposed changes would, however, see fees of up to $£ 1,000$, depending upon the activities undertaken by the data controller.

The Information Commissioner, Richard Thomas, has been calling for greater powers for some time, to bring the ICO's powers into line with other regulators such as The Financial Services Authority. Although both the CJIA and the Consultation appear to be a step in the right direction, as yet the Secretary of State has not exercised the power under the CJIA. Further, the government proposals under the
Consultation do not go as far as the recommendations contained in the datasharing review report compiled by the Information Commissioner and Doctor Mark Walport, ${ }^{3}$ which predates the Consultation by five days. In light of the government's regular high-profile data losses and the public perception of the extent to which personal data is protected however, the ICO undoubtedly has a strong case for demanding greater powers.

\section{DEVELOPMENTS IN THE EU}

As already mentioned, the Directive's aim was to harmonise the data protection laws of the various EU member states. In practice, however, there are differences between the implementing legislation throughout the EU. Further, local regulators throughout the EU member states have taken different approaches to enforcing local data protection legislation. For example, in the UK there is a general obligation for data controllers to notify, subject to certain exceptions, whereas in Ireland, data controllers are only obliged to notify if their type of business appears on a prescribed list. By way of further contrast, in Sweden and Germany data controllers are frequently not required to notify except in certain circumstances. Another area where contrasts exist is that of local regulators' attitudes to transferring personal data outside of the EU. To date, the EU Commission has approved three sets of approved model clauses by which organisations located in an EU member state may transfer personal data outside the EEA. The EU-approved Model Clauses were developed for use throughout the EU, to enable businesses to transfer personal data to organisations based outside the EEA. Different EU regulators, however, take different approaches to data controllers' use of the Model Clauses. For example, in Germany or Sweden companies relying on the Model Clauses need only execute a copy and hold it on file so that it is 
available for inspection by the regulator should the need arise. On the other hand, some EU regulators operate a 'permissiondriven' regime, where the regulator's permission must be granted in order for personal data to be transferred outside the EEA. In such cases, a copy of the Model Clauses must be filed with the local regulator for approval. This process frequently involves the proposed data transfer undergoing considerable scrutiny, and it is by no means a forgone conclusion that the regulator will grant permission. Some regulators, such as the GIODO in Poland, are highly resistant to organisations transferring sensitive personal data outside of their jurisdiction. This can cause considerable problems with multinational and global organisations that transfer personal data, such as HR records, around their organisation throughout the world and where, for example, elements of their HR department are centralised in their global headquarters. The problem occurs frequently where organisations are required to operate whistleblower schemes. This is an issue with US-headquartered multinationals, which may be subject to the Sarbanes-Oxley Act of 2002 (SOX) and as such are legally required to implement a whistleblowing scheme. It is conceivable that operating a whistleblower scheme can involve transfers of sensitive personal data outside the EEA. For example, where there is an allegation of financial impropriety arising from the fact that an employee in the sales department is able to influence an employee in accounts into concealing financial information as the result of a sexual relationship. Some EU data protection regulators, however, simply will not permit the transfer of sensitive personal data outside the EEA despite the fact that a whistleblower scheme is mandatory under US law. This makes it extremely difficult for a US-headquartered multinational to simultaneously comply with its SOX obligations and those of the applicable EU data protection legislation. Such cases make it increasingly apparent that a 'one-size-fitsall' approach to data protection compliance throughout the EU is unworkable.

\section{THE ASIA-PACIFIC ECONOMIC COOPERATION COUNTRIES}

Looking further afield, there are currently considerable developments in the AsiaPacific Economic Cooperation (APEC), a cooperative group comprised of 21 member economies of varying levels of economic and technological development. The aim of APEC is to promote measures to facilitate economic growth, trade and investment in the Asia Pacific region. There is no harmonised data protection approach among APEC members: some have no regulation at all, whereas others have adopted comprehensive laws. APEC members' governments, however, recognise, that a trusted data protection regime assists economic growth and is therefore an important issue. A detailed consideration of the various regimes is beyond the scope of this paper; however, the following examples show the approaches various countries have taken.

In Japan, the Personal Information Protection Act aims to protect personal data; however, the Japanese cabinet office does not have the power to implement it. Accordingly, the guidelines are the key issue for businesses to consider. A criticism is that these guidelines lack consistency. Japan's data protection regime is, however, some way ahead of China's data protection legislation: to date, China has no comprehensive privacy law. The Chinese Academy of Social Science is currently drafting legislation that is likely to be moved forward by the State Council Information Office. A recent celebrity photo scandal in Hong Kong seems to be adding impetus for the legislation. In India, there is no comprehensive data protection law. Proposed amendments to the IT Act of 2000, which introduced criminal 
penalties for data protection breaches, were under parliamentary review but were later rejected. In Taiwan, the Computer Processed Personal Data Protection Law applies only to computer-processed personal data and to a limited range of businesses. This law is enforced by the Ministry of Justice. An amendment bill expanding the scope of the law by extending its application to personal information in any form and any industry and including provisions for sensitive data is currently awaiting passage by the Taiwanese legislature. In South Korea, the Act on Promotion of Information and Communication Network Utilisation and Data Protection (1999) only applies to certain private sector entities and contains an opt-out for e-mail marketing and an opt-in for SMS, phone and fax marketing.

Developments in the APEC countries suggest that each country is seeking its own way to protect personal data. The differences between jurisdictions can be explained by the fact that the APEC countries encompass diverse legal systems, social values and histories. Motivation for implementing a data protection regime is frequently driven by economic growth rather than human rights protection. Only time will tell how such diverse data protection legislative regimes will deal with multinational organisations, given that frequently data protection laws are in an embryonic state.

\section{THE US: DOING ITS OWN THING?}

The US does not have a comprehensive national or federal law governing the processing of personal information. Instead, US data protection law has evolved in a piecemeal way, primarily through industry-specific or data-specific laws at federal and state levels. In addition, even where a federal law covers similar conduct as corresponding state laws, it may not necessarily pre-empt or override such state law requirements. Of this patchwork of laws, probably the most broadly applicable are the Health Insurance Portability and Accountability Act, commonly known as 'HIPAA', which applies to health plan providers; the Fair Credit Reporting Act, which regulates credit referencing activities; and the Gramm-Leach-Bliley Financial Services Modernization Act (GLB), which governs financial institutions. The Children's Online Privacy Protection Act, frequently referred to as COPPA, regulates website operators who collect personal data online. What is noticeable by its absence is a comprehensive data protection law.

Perhaps a closer parallel to the legislation adopted by the EU and much of APAC is the recently enacted 'security breach notification' legislation, which operates at a state level. Not unlike the experience in the UK, in the US recent years have witnessed a large number of security breaches, which have led to an increased public awareness. In response, many states enacted legislation paralleling California's Security Breach Bill of 2003, which provides for notification to be given to individuals whose personal information is compromised.

To date, 46 state data breach laws have been enacted. The state laws are generally similar, but there are differences between each. Some of the laws are aimed specifically to protect against identity theft and financial loss. These laws incorporate a materiality requirement or threshold of harm before notification is required. Some states have limited the scope of their applicable law to those entities that are most likely to process large amounts of personal information, such as data brokers and government entities. Other state laws apply to all data controllers, and do not exclude entities already under the jurisdiction of federal or state privacy legislation such as GLB or HIPAA. The large number of separate state data privacy laws, each with its own scope and 
requirements as to the level of breach that must be notified, means that data controllers operating in the US should consider each separate law to ensure compliance.

Frequently, US state security breach notification laws define 'personal information' much more narrowly than EU data protection legislation. Some state laws limit the definition to personal data that enables a person to commit identity theft. The common theme among the state laws is that they require data subjects residing in the state to be notified if their personal data information has been compromised. Some states, however, impose additional EU-style data protection principles such as the requirement to process personal data securely, including mandatory encryption for data transfers, the use of contractual safeguards and data-destruction policies.

Interestingly, some of the US state data breach laws address two issues that have been suggested as deficiencies in EU data protection law: (i) the recognition of financial data as a category of personal data that requires special treatment and (ii) the requirement that data controllers notify data subjects of breaches. On the second point, of compulsory data security breach notification, although there are many proponents of mandatory security breach notification, this approach has recognised weaknesses. In the UK, for example, ICO guidance $^{4}$ states that 'informing people about a breach is not on end in itself'. A suggestion that has emerged following the many government data losses in the UK is that compulsory notification may do more harm than good. For example, where a data security breach involves the loss or theft of a laptop, the thief may not necessarily realise the value of the data but for the publicity in the press.

\section{CONCLUSION}

The current data protection picture, taken at a global level, shows at least three trends.
In the EU, data protection laws have been in force for many years, and the legislation and regulators are tried and tested. In this environment, interested groups are able to see where there is need for changes in the law and, where necessary, further legislation should be put into place. The EU data protection legislative regime is well established, sophisticated, subject to ongoing refinement and fundamentally driven by the protection of human rights laws. As such, EU data protection legislation is primarily aimed at protecting individuals' rights. Many of the APEC countries recognise the value of data protection legislation; indeed, some APEC countries recognise that they will be unable to compete in the world economy without being able to guarantee the protection of personal data. ${ }^{5}$

Accordingly, in some APEC countries, data protection laws have been passed recently, or are in the process of being enacted, to encourage trade with the rest of the world rather than to protect human rights. That is not to say this is the story throughout the region: other APEC countries are more similar to the EU model.

Of the jurisdictions considered above, the US is the odd man out. There is no comprehensive data protection law, nor any apparent appetite to enact one. The disparate state data security breach laws, however, go some way to protect individual rights.

Although legislation exists to protect personal data, it is difficult to see whether the motivation is to protect business interests, or the rights of individuals.

The examples of data protection legislative regimes we have considered demonstrate the very different approaches taken by different jurisdictions. This is even the case in the EU, where the Directive was intended to harmonise individual member states' data protection laws. The differences are more pronounced still when we look at them at the global level.

Accordingly, it should come as no surprise that for a multinational organisation 
intending to achieve global compliance with the many data protection laws applicable to its overseas offices, a 'onesize-fits-all' approach is unlikely to be effective, and achieving compliance with the many different laws will be no small undertaking.

\section{References and Notes}

1 ICO (2008) 'UK consumers wake up to privacy', Press release. 19th March, http://www.ico.gov.uk/ upload/documents/pressreleases/2008/information_ rights_press_release_final1.pdf.

2 Ministry of Justice Consultation Paper 'The Information Commissioners' inspection powers and funding arrangements under the Data Protection Act 1998, published 16th July, 2008.

3 R Thomas and Dr M Walport Data sharing review, December 2007.

4 Information Commissioner's Office (2008)

'Guidance on data security breach management', March.

5 See for example Brown, A. (2008) 'Pakistan IT guidelines to precede data protection law', Data Protection Law and Policy, Vol. 5, No. 9, front page. 